\title{
LA CONSTITUCIÓN COMO PACTO
}

MIGUEL HERRERO DE MIÑÓN 


\title{
LA CONSTITUCIÓN COMO PACTO
}

POR

\author{
MIGUEL HERRERO DE MIÑÓN
}

1. "Voy a hablaros de problemas constitucionales; de lo que es una Constitución". Estas palabras de Fernando Lassalle pronunciadas en 1862, en Berlín, parecen dichas, como ahora es el caso, para celebrar una efemérides constitucional. Porque, siguiendo con la cita textual de Lassalle", "por todas partes y a todas horas, tarde, mañana y noche, estamos oyendo hablar de Constitución y de problemas constitucionales $y$, sin embargo, formulada en términos precisos esta pregunta: '¿En qué está la verdadera esencia, el verdadero concepto de una Constitución?', mucho me temo que, entre tantos y tantos como hablan de ello, no haya más que unos pocos, muy pocos, que puedan dar una contestación satisfactorian.

Muchas son las posibles maneras de responder a la pregunta que formulaba Lassalle, y el orador berlinés no dejaba ya de lanzar ciertas ironias y reticencias a la respuesta que un jurista pudiera darle. $\mathrm{Pe}$ ro un jurista consciente de que el derecho no existe de suyo, sino que, como dijera Savigny, es la vida misma vista desde una específica perspectiva, si es capaz de dar una repuesta satisfactoria a la pregunta en cuestión. Satisfactoria, incluso, para los no juristas, para los políticos entre otros, conscientes de que el derecho y la Constitución como su

1 Verfassungswessen, l, 2 (ed. Bernstein, 2, pp. 425 ss). 
piedra angular, es una herramienta práctica para la solución de conflictos. En el caso del derecho constitucional, nada menos que de conflictos de poder.

Para empezar y utilizando las categorías de Löwenstein, es preciso huir de la noción semántica de la Constitución, mero reflejo formal de una situación de poder, o de las que se llaman nominales, es decir, las retóricas sin enérgica pretensión de validez, propia del derecho, y atenerse a la noción normativa de Constitución. Pero, dicho esto, nos encontramos, como Edipo, ante una gravisima encrucijada. Porque en la primera mitad de este siglo $y$ en torno a dos nombres señeros, Kelsen y Schmitt, se ha discutido hasta la saciedad por los juristas si la Constitución era una norma suprema a la que podía y debía reducirse todo el ordenamiento jurídico, o la Constitución era, en frase de Schmitt, "una suprema decisión existencial sobre el modo y forma de la vida política en un país" ${ }^{2}$. A mi entender, aunque se han opuesto entre sí ambas nociones, pueden considerarse frutos de una misma raíz: la noción de soberanía como poder supremo, absoluto e indivisible; de decisión soberana del constituyente que cristaliza en una norma suprema.

Tanto normativismo como decisionismo son vías erróneas para explicar lo que una Constitución es, y especialmente para explicar lo que es nuestra Constitución de 1978. Son caminos erróneos porque errónea es su raíz: la noción de soberanía como un poder incondicional, ilimitado, absoluto, ejemplo típico de lo que Ortega llamaba «palabras de presa» ${ }^{3}$. A mi juicio, hay que desandar el camino mal andado y volver a los orígenes, volver a la encrucijada donde se tomó el mal camino para encontrar otra vía. Hay que llevar a cabo una destrucción heideggeriana de la interpretación decisionista y normativista de la Constitución, para concluir que la Constitución en general y la Constitución española en particular, es un pacto, un gran pacto de Estado, y como tal pacto debe ser interpretada.

Efectivamente, si a través de esa destrucción heideggeriana se diluye la costra de tópicos - aunque sean a veces tópicos especial-mente brillantes - que se han construido en torno al normativismo y decisionismo, encontramos que, bajo la norma, lo que existe es un pac-

2 Vervassungslehre, Berlín, 1934. Sobre el conflicto de interpretaciones en la doctrina de Weimar, cf. Lucas Verdú, La lucha contra el positivismo jurídico en la República de Weimar, Madrid, 1987.

3 Sigo la crítica de B. DE JOUvENEL, La souveraineté, París, 1956. 
to, un compromiso. Lo es asi históricamente, desde los viejos tiempos en que se acuñara la célebre expresión romana según la cual Lex est conmunis reipublicae sponsio, frase que Bracton divulgó en la Inglaterra medieval, de donde saltó al Continente y ha llegado a constituir, como señala Mcllwain ${ }^{4}$, la esencia del constitucionalismo. Sin consentimiento de las partes no existe ley.

Sin duda, cuando se generalizan y popularizan y asumen por los juristas las fórmulas filosóficas de Rousseau, se dice que la ley es una expresión de la voluntad general y, en consecuencia, que la Constitución es la expresión de la decisión soberana del poder constituyente ${ }^{5}$.

El decisionismo substituye, así, al pactismo. Pero siempre cabrá preguntarse por lo que hay debajo de esa decisión. $Y$ resulta que debajo de la decisión también nos encontramos con el pacto y el compromiso. Porque ni en la Ciudad Antigua, ni en la moderna sociedad industrial o postindustrial existe una unidad política homogénea e indivisa ${ }^{6}$.

Ya lo decía Cicerón en su pequeño tratado Sobre el Estado, cuando afirmaba que la concordia se obtiene por el concurso y el acuerdo entre gentes y naciones de diversa índole. $Y$ hoy mismo, desde un punto de vista realista, hay que reconocer que no existe un pueblo "soberano", que no hubo "Nosotros, el pueblo de los Estados Unidos...", sino, como apuntara $\mathrm{Ch}$. Beard ${ }^{7}$, una muy concreta policracia, que no otra cosa es la pluralidad de intereses organizados. Estas son nociones metafísicas, en el peor de los sentidos que al término debiéramos dar los juristas, después de León Duguit.

Bajo la decisión, cualquiera que sea el sujeto al que la misma se impute - una nación, una voluntad soberana, un pueblo soberano-se cobija el compromiso y el pacto de una pluralidad de entes. Gentes en la Ciudad Antigua, estamentos en la comunidad medieval, y hoy fuerzas políticas y sociales de la más diversa índole. Pero que siempre será una realidad policrática, cuyos elementos pactan entre sí. Así lo vio, como ha subrayado el ilustre Pierre Mesnard ${ }^{8}$, quien pasa por ser el

4 Constitutionalism. Ancient and Modern, Ithaca, 1947.

5 Cf. Duclos, La notion de Constitution dans l'oeuvre de l'Assemblée Constituante de 1789, París, 1932, pp. 178 ss.

6 Sigo a B. DE JOUVENEL en Du Pouvoir, Ginebra, 1945.

7 An economic interpretation of the Constitution of the United States, Nueva York, 1913.

8 Cf. Mesnard, Jean Bodin en la Historia del Pensamiento Político, Madrid, 1952, pp. 71 ss. 
gran teórico de la soberanía moderna, pero que era un sociólogo realista, el gran Juan Bodin. Y otro tanto cabe decir de las viejas Cartas Otorgadas - que nunca fueron otorgadas por un Monarca, sino pactadas entre el Monarca y su pueblo, como demostrara P. Bastide - 0 del carácter pactista que tuvo la obra de Filadelfia de 1786 entre los constituyentes y sus diversas tendencias, según resulta de las páginas ya clásicas del Federalista.

Pero, precisamente por eso, aunque no sólo por eso, la Constitución es además de norma, la expresión de un proceso que R. Smend9 calificó de integración. Si lo es por los símbolos que consagra, por los valores que proclama, por las instituciones que organiza, también lo es porque el constituyente incorpora e incoa una función de unidad. Pero eso no se hace por imposición unilateral, sino por vía de pacto.

Ahora bien, al disolver en ácido pactista lo que Karl Schmitt denominaba la "decisión unilateral e incondicional del poder constituyente", ese decisionismo que late también bajo el normativismo, nos encontramos con casos en los que la incorporación consensuada es no sólo un concurso de intereses, sino un verdadero pacto constitucional, aquél que según Schmitt requiere, al menos, dos sujetos preexistentes y subsistentes. Es decir, tal supuesto no se reduce sólo a un pacto federal, sino que está en la base de algunas constituciones, entre otras, de nuestra Constitución.

2. Decimos todos, y creo que es el mayor título de gloria de nuestra Constitución, que es una Constitución consensuada. Pues bien, ¿qué es una Constitución consensuada si no es una Constitución pactada? ${ }^{10} \mathrm{Y}$ no vale decir que formalmente la Constitución es obra de un constituyente soberano, aunque material y políticamente sea una Constitución pactada, porque eso sería reducir las formas a cascarones vacios, absolutamente ajenos a la realidad. Si reconocemos y nadie lo discute, y hay suficientes pruebas de ello en las Actas de la Ponencia Constitucional e, incluso, en los Diarios de Sesiones del Congreso y del Senado de las Cortes Constituyentes y de las legislaturas ulteriores, que nuestra Constitución fue una Constitución pactada, los juristas tienen que sacar las consecuencias de esa realidad política, porque el de-

9 Cf. Verfassung und Verfassungsrecht, Munich, 1928.

10 Cf. Peces-Barba, La Constitución Española de 1978, Valencia, 1981, p. 13. Cf. D. S. (Congreso), 20 de junio de 1978, pp. 3495 ss. Así va afirmando la más autorizada doctrina, vid., por ejemplo, la $4 .^{a}$ ed. de los Principios de Derecho Constitucional, de A. TORRES Del Moral. 
recho político tiene por objeto la política y, o trata de razonar jurídicamente sobre la realidad política, o razona en la irrealidad, es decir, no razona11.

La Constitución, por consensuada, fue pactada. Cabe y debe preguntarse entre quiénes, sobre qué y cómo se hizo este pacto. $Y$ tales son los elementos subjetivos, objetivos y de la actividad que toda buena teoría general utiliza a la hora de analizar cualquier negocio jurídico.

¿Quienes son los sujetos del pacto constitucional? Esos sujetos que no sólo crearon, sino que, con frase del viejo catecismo, están siempre presentes por esencia, porque mantienen viva a la Constitución, dándole el ser día a día. Para saber quienes son estos protagonistas constituyentes del consenso es preciso distinguir entre sujetos y actores $^{12}$. Por una parte, habia unos sujetos formales del poder constituyente: los que tenían competencia de, en virtud de la Ley para la Reforma Política, hacer una nueva Constitución. Las Cortes, que la elaboraron; el Pueblo, que la refrendó; el Rey, que convocó aquéllas y promulgó y ordenó la publicación de ésta. Pero, además de tales sujetos formales, hay unos actores políticos que son también protagonistas del proceso de poder, lo que Lassalle denomina ufragmentos de la Constitución viva».

Se dice, cuando se habla de aquél gran fenómeno político que fue el consenso, que lo protagonizamos los siete ponentes de la Constitución. Eso es verdad, pero no toda, porque es cierto, además, que lo protagonizaron los dirigentes de los grandes partidos políticos que entonces articulaban el Congreso de los Diputados y el Senado. $Y$ eso es verdad, pero no toda, porque es cierto que esos dirigentes, por grandes que fueran sus cualidades, no eran más que los órganos de lo que Gramsci denomina el Príncipe de la política de nuestros días, es decir, los partidos políticos. Sin duda los partidos políticos - UCD, el PSOE, el Partido Comunista, Alianza. Popular, Convergencia de Cataluña, el Partido Nacionalista Vasco en cierta medida- protagonizaron aquel proceso. $Y$ esto es verdad, pero no es toda la verdad; no es más que,

11 Cf. Rubio, La Forma del Poder, Madrid, 1993, pp. 49 ss. Sobre este asunto arrojan luz decisiva los estudios de M. Rivas sobre la Génesis del Título Primero de la Constitución Española de 1978 en el seno de la Ponencia (Tesis Doctoral), Madrid, 1998, en vias de publicación. Una primera y aguda aproximación en Ramirez, Partidos Políticos y Constitución (Un estudio de las actitudes parlamentarias durante el proceso de creación constitucional), Madrid, 1989.

12 Cf. Garcia Pelayo, Las transformaciones del Estado contemporáneo, Madrid, 1977, p. 108; RuBio, op. cit., p. 11. 
como ocurre con los icebergs, la cumbre emergente de una masa mucho mayor: el consenso social y político de los españoles. Los protagonistas del consenso, individuales y colectivos, hicieron lo que hicieron porque así se lo exigía e imponía la sociedad española.

Y la sociedad no es una abstracción homogénea e indivisible; la sociedad es el conjunto de instituciones, de fuerzas, de entidades de todo tipo, y, por eso, el consenso fue obra no sólo de siete ponentes, o de dos vicepresidentes o vicesecretarios de partidos políticos, o ni siquiera de las grandes fuerzas políticas. Fue obra también del pacto de elementos sociales de diversa índole, desde la Iglesia a la Patronal, pasando por los Sindicatos; de instituciones históricas, de entidades territoriales, etc. Releyamos a Lassalle, que parece escribir para hoy cuando dice, por ejemplo: «Un Rey a quien obedece el Ejército y los cañones es un fragmento vivo de Constitución. Unas entidades territoriales históricas influyentes son también fragmentos de Constitución. Los grandes industriales todos son también un fragmento de Constitución. Los grandes banqueros son también un fragmento de Constitución. La conciencia colectiva y la cultura general del país son un fragmento de Constitución». Y termina, dirigiéndose precisamente a los que consideraba más marginados y trataba de sublevar: "También ustedes, señores, todos ustedes juntos, son un fragmento vivo de Constitución". Yo creo que eso fue realidad no sólo en la Prusia de Lassalle, sino que fue realidad en la España de 1978.

Lo que pactaron los actores del proceso constituyente fue su propio "status", es decir, el objeto de la Constitución. Los sujetos y el objeto fueron lo mismo. Pero de esto no hay que extrañarse, porque es lo normal en los órdenes concretos, configurados por un "pacto de status» en el que quienes participan, entran en un nuevo orden de vida. ¿Acaso en el matrimonio, al menos en su concepción tradicional, no ocurre eso? ¿No son los contrayentes los que contraen sobre sí mismos? Porque - con esto pasamos al segundo de los grandes elementos a analizar - ¿qué es lo que se pacta?

¿Qué es lo que se pacta en un proceso constituyente, concretamente en nuestro proceso constituyente? Técnicamente se hacian transacciones sobre todo. De esto hay suficiente material para los historiadores en las Actas de la Ponencia Constitucional o en los Diarios de Sesiones del Congreso y del Senado. Sobre lo principal -la Nación española en el artículo 2- o lo secundario - la Seguridad Social en el artículo $41-$; mediante fórmulas auténticamente transaccionales - sobre la Iglesia en el artículo 16- mediante elusiones - sobre el Senado, en el artículo 69- o mediante compromisos apócrifos -sobre la huelga 
en el artículo 27-13. Pero el pacto fundamental, la Constitución en sentido positivo, es sobre el "status" de las tres realidades que, a mi juicio, preexisten a la Constitución y se insertan en ella; sin derivar su existencia de la Constitución, sino que antes bien son su fundamento o raíces vitales. Me refiero a la Monarquía, a las libertades y a las nacionalidades históricas ${ }^{14}$.

Los constituyentes encontramos esas tres realidades pre y para constitucionales y las insertamos en la norma fundamental. Pero es claro que no las creamos. Por ello se ha dicho que al proceso constituyente formal precedió un proceso constituyente implicito ${ }^{15}$, cuyo hito fundamental sería la Ley para la Reforma Política de 1976. Pero ni la Monarquía traía su existencia de esta octava ley Fundamental, sino que transcendía el ordenamiento "franquista" y así lo reconoció el propio constituyente; los derechos humanos son un valor entendido para la Ley de 1976 (art. 1); y el restablecimiento de la foralidad provincial de donde arranca el Consejo General Vasco, y de la Generalitat Catalana, no crean, sino que restauran. Actualizan una potencialidad histórica, se diría después.

La Monarquía no deriva de la Constitución. Se inserta en ella, pero tiene una realidad preconstitucional y paraconstitucional. Es claro que la Monarquía precede a la Constitución e incluso la hace posible. Puede argumentarse política y sociológicamente, puesto que en España la Corona está funcionando $y$, sobre todo, funcionó en el momento constituyente $y$ en algunos ulteriores bien conocidos, como lo que Weber denomina "un estrato protector de la legalidad constitucional». Pero es que además puede argumentarse jurídicamente, puesto que de la exorbitancia que respecto de la norma constitucional tiene la Monarquía existen huellas en la propia Constitución. Por ejemplo: la legitimidad histórica que, al referirse a la persona del Rey, la Constitución afirma (art. 57); o la titulación tradicional (art. 56) y, sobre todo, al hecho del juramento real. El Rey no juró la Constitución en 1978 upara ser Rey", sino, "porque era Rey" la promulgó. $Y$ esto no es un accidente, sino que el artículo 61 de la Constitución lo establece como norma general: el Rey no jura la Constitución para ser Rey, sino que la jura por-

13 Cf. mi temprano trabajo, "Falsas y verdaderas vias del consenso constitucional», en Revista de Estudios Políticos, n. ${ }^{\circ}$ 9, 1979, pp. 73 ss.

14 Cf. mi intervención el 5 de mayo de 1978 en el Congreso sobre el dictamen de la Ponencia Constitucional, recogida en Ideas para Moderados, Madrid, 1982, pp. 259 ss.

15 Rubio, op. cit., p. 52. 
que es Rey, como el año 76 del pasado siglo lo afirmaba don Antonio Cánovas. La prueba de ello es que el Rey es Rey cuando es menor de edad, incluso desde su nacimiento si es hijo póstumo. $Y$ precisamente porque es Rey, al llegar a la mayoría de edad jura la Constitución. No como los funcionarios que, precisamente para tomar posesión, para adquirir su calidad de funcionarios, prestan juramento.

Pero, si esto es así de la Monarquía, es claro que será aún menos discutible de los derechos humanos, de las libertades públicas y de los derechos ciudadanos que, según el artículo 10, son el fundamento del orden jurídico y constitucional y que la Constitución reconoce, porque preexistían al propio constituyente. Preexistían en la mentalidad colectiva que, como decía Lassalle, era un fragmento vivo de la Constitución. Era imposible, por la fuerza normativa de los hechos en el año 1978, que la Constitución no recogiera la Monarquía, y era igualmente imposible que no reconociera los derechos humanos del contorno europeo en el que España se movía, y que ya estaban vivos y con exigencia y urgencia en la conciencia de los españoles.

Llegamos así a un tercer elemento de este gran pacto fundamental, que a mi juicio también preexistía a la Constitución: el derecho a la autonomía de las nacionalidades históricas reconocido en el artículo 2 de la Constitución y reiterado a través de la categoría de Derechos Históricos en la disposición Adicional Primera de la norma fundamental. De la literalidad de estos preceptos, de su sistemática, de su decantación constituyente, resulta que se configura el derecho a la autonomía de las nacionalidades históricas como algo previo a la propia Constitución. Por eso, cuando en las Constituyentes se discutió la redacción del artículo 2, se enfrentaron dos tesis: la que decía que la Constitución fundamentaba el derecho a la autonomía y la que decía que reconoce el derecho a la autonomía ${ }^{16}$. Y, por supuesto, prevaleció la segunda, porque el derecho a la autonomía es una realidad, la de un derecho a ser, que la Constitución puede reconocer, pero que preexiste a la Constitución y que no ha de pasar, incluso, si la Constitución "pasase" 17.

Por otra parte, la Disposición Adicional Primera supone la apertura de la normatividad constitucional a una historicidad pre y para constitucional que incorpora e integra, pero porque "ampara y respeta» ${ }^{18}$.

16 D.S. (Congreso), 12 de mayo de 1978, p. 2305.

17 D. S. (Congreso), 12 de mayo 1978, p. 2308.

18 Cf. mi Idea de los Derechos Históricos, Madrid, 1991. 
El Tribunal Constitucional no lo ha entendido así y ha rechazado expresamente la idea de factores extraconstitucionales y pacto constituyente (S.T.C. 76/88, FJ 3). ¡E pur si muove! La Constitución en sentido positivo remite así a la Constitución substancial. Pero no se trata de una decisión, como pretendiera el primer Schmitt, ni de unos principios normativos, como mantendrían los doctrinarios de la Constitución material, sino de la formalización constitucional de unos fragmentos de historicidad, previos al, e, incluso, protagonistas, del proceso constituyente.

Ciertamente que las permanentes mutaciones constitucionales e incluso el cambio de las circunstancias económicas, sociales y políticas que inciden en la estructura constitucional puede llevar a modificaciones substanciales en los actores del proceso constituyente. La secularización puede acabar con el poder de las Iglesias, la inflación arruinar a una clase propietaria, el pacifismo acabar con el prestigio militar. $Y$ ya Jellinek ${ }^{19}$ señaló que las instituciones pueden quedarse sin contenido $y$, en consecuencia, sin fuerza y esto puede ocurrirle a cualquiera de los fragmentos de Constitución antes mencionados o por mencionar. El pacto constituyente, que no está en el origen, sino en la base de la Constitución, ha de entenderse que vincula a los actores efectivos del consenso, sean o no los originales. Pero es claro que en España los cambios, indudablemente ocurridos en estos veinte años, no han eliminado ninguno de los fragmentos de Constitución o, utilizando otras palabras, ninguno de los actores del proceso constituyente. Los partidos político son aún más sólidos y estables que hace dos décadas; las identidades nacionales, más indiscutibles; la Corona, más prestigiosa; las fuerzas sociales tienen mayor sintonía con la conciencia ciudadana. Los actores del pacto constituyente originario siguen siendo los del pacto constituyente "por esencia»; el que permanentemente da el ser.

Cabría preguntarse en fin cómo se hizo ese pacto. Sin duda, hay elementos pactistas fácticos en el proceso constituyente y carece de lógica elogiarlos políticamente para después negarles relevancia a la hora de la interpretación jurídica, a pesar de ser "antecedentes históricos y legislativos", de los que el Código Civil menciona como criterios heurísticos (art. 3). Pero además, existen elementos pactistas formales en el bloque de constitucionalidad. Así, los Estatutos que se elaboran sobre la base del artículo 151 de la Constitución, sin perjuicio de que des1991, p. 57.

19 Reforma y mutación de la Constitución, (1906), trad. española, Madrid, 
pués se formalicen en una Ley Orgánica, obra unilateral de las Cortes Generales, se decantan a través de una serie de actos-procedimiento o de actos complejos que, en realidad, recubren pactos entre instancias de la Comunidad en cuestión y de su propio pueblo con el Estado ${ }^{20}$. Y, además, hay Estatutos a los que el Tribunal Constitucional niega todo carácter diferenciado, y sin embargo lo tienen, como es el caso de la Ley Orgánica del Amejoramiento del Fuero Navarro del año 83, donde hasta la saciedad se afirma el çarácter pactado de ese Estatuto ${ }^{21 .}$

Ahora bien: más allá de estos elementos de hecho o derecho $-y$ que todos tiene que tomar en cuenta el jurista - yo me atrevo a decir, después de lo expuesto, que toda la Constitución se pacta. No porque muchas de sus cláusulas sean fruto de una transacción, sino por algo más hondo que posibilitó la transición: el concurso de voluntades en torno a una meta superior.

Se pacta, no mediante el enfrentamiento de intereses encontrados, que se compensan en un do ut des o en un do ut facias, sino por la promoción conjunta de un interés común. Es decir, la Constitución es un pacto, pero no es un contrato. La Constitución es una unión de voluntades porque no supone que fuerzas sociales y políticas, entidades territoriales o instituciones históricas se enfrenten entre sí y tengan recíprocamente que ceder ante intereses opuestos de la otra. Creo que esa es una maneara errónea de interpretar el consenso, en que no se trató tanto de ceder todos frente a la pretensión ajena, sino en unir todos voluntades, porque los intereses no eran contrapuestos, sino coincidentes en torno a un fin. En esto consiste la "vereinbarung" que acuñó la doctrina alemana y después se difundió por toda Europa y de ella emergen lo que Guasp denominaba, depurando a Romano, Hariou y el propio C. Schmitt, instituciones 22 .

3. ¿Qué consecuencias tiene que la Constitución sea un pacto? Al menos tres. De un lado, la inderogabilidad unilateral de la Constitución y de sus instituciones, ni siquiera a través del procedimiento de reforma de la Constitución. Cuando se dice - para poner el ejemplo que puede resultar más polémico y a la vez menos doloroso- que los Es-

20 Cf. TRuJillo, "Los procedimientos estatutarios desde la perspectiva del acto complejo", en Los procesos de formación de las Comunidades Autónomas. Aspectos jurídicos y perspectivas jurídicas, Granada, 1984.

21 Cf. el significativo prólogo de García de Enterría a J. I. DEL BURGo, Introducción al Amejoramiento del fuero, Pamplona, 1987. Mi propia interpretación en Derechos Históricos y Constitución, Madrid, 1998, cap. XIV.

22 Cf. GuAsp, Derecho, Madrid, 1971, pp. 459 ss. 
tatutos de Autonomía aprobados por la vía del 151 no pueden ser unilateralmente modificados más que a través de la reforma de la Constitución, en el fondo se está diciendo que pueden ser unilateralmente modificados, puesto que se los hace derivar de una Constitución; que el Parlamento -es decir, las Cortes Generales - y el Pueblo mediante referéndum pueden modificarlos unilateralmente ${ }^{23}$. Pero un pacto no puede ser unilateralmente modificado ni siquiera por los ciudadanos.

Hacerlo sería no modificar la Constitución, sino destruirla y ya Schmitt puso de relieve lo irreal que es tomar el procedimiento de revisión constitucional, útil a la hora de modificar las normas legal-constitucionales, para alterar los fundamentos de la Constitución positiva. Si unilateralmente se altera el pacto constituyente, lo que se destruye es la Constitución substancial y cae todo lo demás. ¿Es acaso imaginable que las mayorías cualificadas del artículo 167.2 CE pudieran revisar el artículo 149 o derogar la Adicional Primera sin consecuencias diferentes a la reforma de extremo técnicamente tan importante como el artículo 113 ?

Por ello la revisión constitucional, incluso la relativa a elementos secundarios, se ha abordado y llevado a cabo mediante amplio consenso - v. gr. en 1992 la del art. $13 \mathrm{CE}-\mathrm{y}$ cuando no se ha contado con tal consenso, el proyecto se ha abandonado - v. gr. la reforma del Senado-.

Pero esta condición pactada de la Constitución no sólo tiene que tener un efecto conservador - simul stabunt simul cadunt- sino que también señala el cauce para la innovación. Puesto que por la misma razón que el pacto no puede ser modificado sin el acuerdo de las partes, mediando éste se puede, no sólo revisar la Constitución, sino incluso mutarla sin alterar su texto. Así, por ejemplo, cuando la finalidad de paz inherente y esencial al Estado, pudiera ser mejor servida, reinterpretando e incluso forzando el sentido de los textos constitucionales, la reactivación del pacto constituyente sería la vía idónea para conseguirlo. Si el pacto, y no de todos, dio lugar en 1981, según la más acreditada doctrina, a convenciones constitucionales, el pacto aún más amplio podría dar lugar a otras en sentido diferente. Si las primeras generalizaron el régimen autonómico y lo homogeneizaron, las segundas podrían servir para reconocer la exorbitancia, respecto del Título VIII, de determinados hechos diferenciales. Basta para ello reinterpretar, y

23 Cf. Garcia de Enterria, Estudios sobre Autonomías Territoriales, Madrid, 1985. 
no falta base jurídica al efecto, el "marco" de la Constitución que, con moderna versión de la "unidad constitucional de la Monarquía», establece la Disposición Adicional Primera.

En segundo término, es claro que la naturaleza pactada de la Constitución exige el consenso de su desarrollo. Algo especialmente importante en una Constitución eminentemente "abierta" como la española es. Y, curiosamente, aunque más de una vez se ha dicho lo contrario, este carácter consensuado del desarrollo constitucional se ha mantenido a lo largo de estos veinte años en contraste con la creciente conflictividad política a otros niveles.

Este pacto para el desarrollo ha sido evidente en lo que se refiere a las instituciones. Así, todo lo relativo a las Autonomías, desde los Acuerdos Autonómicos de 1981; a las Fuerzas Armadas, desde 1980; e instituciones secundarias de relieve constitucional como el Consejo de Estado (Ley 3/1980, de 22 de abril) o el Defensor del Pueblo (Ley 3/1981, de 6 de abril). Otro tanto puede decirse de las garantías democráticas -v. gr. la suspensión de los derechos fundamentales (Ley 4/1981, de 1 de junio) - $y$, muy espcialmente, de la legislación electoral general (Ley $5 / 1985$, de 19 de junio). $Y$ es de destacar que, en todos estos casos, el consenso se ha buscado cuando el Gobierno de uno u otro signo contaba, incluso sólo de 1982 a 1993, con la mayoría parlamentaria absoluta y suficiente para hacer las necesarias Leyes Orgánicas. Sobre las exigencias de la técnica legislativa ha primado el imperativo del consenso, solamente abandonado en una ocasión secundaria sobre la composición del Consejo General del Poder Judicial ${ }^{24}$.

De otra parte, si en el desarrollo legislativo de los valores consagrados en el Título I CE parece haberse abandonado el principio de acuerdo necesario entre las partes del pacto constitucional - v. gr. leyes sobre la enseñanza, en desarrollo del artículo 27 , o del aborto, con relación al artículo 15- la interpretación puede ser otra. La interpretación unilateral de lo inicialmente pactado, ha sido posible porque el pacto inicial era lo suficientemente limitado para dejar abierta esta posibilidad. Tal fue el caso de los compromisos apócrifos, frecuentemente utilizados en el proceso constituyente para consensuar una fórmula, aun a sabiendas de que la ambigüedad de los términos empleados - «todos» en el artículo 15; "intervendrán en el control», en el artículo 20.7; "formas de matrimonio", en el artículo 32; o "mercado" en el ar-

24 Sobre estos extremos, puede consultarse la decantación del consenso en los respectivos trabajos parlamentarios publicados por las Cortes Generales. 
tículo 38- permitía un acuerdo sobre las palabras, manteniendo un desacuerdo sobre el significado. Se pactó así la posibilidad de discrepar sobre los valores con los que dar contenido a los vocablos consensuados. $Y$ así lo interpretó el Tribunal Constitucional.

De ello podrá deducirse que, a lo largo de estos veinte años, se ha decantado, si no una costumbre, sí al menos una convención constitucional relativa a la modificación y desarrollo de la Constitución. Si la primera no podría, en ningún caso, derogar ni suplir el derecho estricto contenido, respectivamente, en el Título $X$ y artículo 81 de la norma fundamental, la segunda puede modular su ejercicio ${ }^{25}$. De esta manera, en ese espacio intermedio entre la práctica del derecho y la práctica de la política en que las convenciones nacen y se desarrollan, cabrá afirmar que, sin previo consenso, no basta la mayoría absoluta del Congreso y del Senado para modificar el régimen electoral general, a pesar del tenor expreso del artículo $81 \mathrm{CE}$, o las mayorías cualificadas del artículo 167 para reformar la Constitución. Precisamente el recurso al referéndum (art. 167.3) por parte de la minoría puede ser, a estos efectos, garantía disuasoria más que una válvula de seguridad.

Claro es que esta convención nada tiene que ver con la práctica no menos extendida de ampliar el pacto al reparto de los órganos constitucionales mediante el sistema de cuotas. Con ello, si se mantiene aparentemente el consenso, se substituye la unión de voluntades por la contraposición de intereses que la distribución satisface singularmente. $Y$, a mi entender, se pervierten las propias instituciones constitucionales afectadas, tanto en su estructura -independencia- como en su función - control-.

Por último, lo que no puede ser derogado ni desarrollado unilateralmente, tampoco puede ser interpretado unilateralmente. Este es un principio de teoría general que recoge el Código Civil y que no sirve sólo para contratos de arrendamiento; tiene que servir lógicamente para algo tan importante como es un pacto constitucional. La Constitución no puede interpretarse unilateralmente, ni siquiera cuando lo hace el Tribunal Constitucional. Una Constitución pactada exige que se interprete pactando día a día.

25 Así lo ha reconocido la doctrina española en otros casos, v. gr. respecto de los Acuerdos Autonómicos, cf. GARCiA DE ENTERRIA, Estudios..., cit., p. 432, con relación a la tesis de VANDELLI, El ordenamiento español de las Comunidades Autónomas, Madrid, 1982, o con relación a la recepción de la tesis pactista de la foralidad navarra, cf. Santamaria PAstor, en Martín Retortillo, ed., El Derecho Público Foral de Navarra. El Amejoramiento del Fuero, Madrid, 1992, pp. 51 ss. 
Esta sensibilidad no ha estado siempre presente en la doctrina del Tribunal Constitucional, que ha autointerpretado sus funciones en sentido estrictamente jurisdiccional, con excesivo olvido de la utilidad que el arbitraje y aun la mediación pueden tener para el buen funcionamiento de un sistema complejo y consensuado como el hoy vigente en España. Tal vez ello hace más necesario la revitalización de las instancias mediadoras.

Por último, todo lo expuesto permite hacer algunas consideraciones sobre categorias tan sugestivas como "lealtad constitucional" o "sentimiento constitucional», susceptibles de quedarse en pura retórica.

El objeto de la lealtad $y$ el sentimiento constitucional no puede ser la literalidad de un texto, aunque no debe desvalorizarse en demasía éste, sino su substancia y su espíritu. Y este es un espíritu de pacto, que supone el reconocimiento del otro; de transacción, que implica la capacidad de ceder; de consenso, que exige la asunción de metas comunes a toda la ciudadanía y a la policracia que la articula y vertebra.

Si la cotidianeidad política no puede estar presidida en todo momento por el espíritu del consenso y la propia Constitución abre un amplio espacio al pluralismo (art. 1.1) y al conflicto a él inherente, también es preciso recordar que la radicalización del conflicto político puede llegar a afectar al consenso constitucional básico.

En el texto ya mencionado de Cicerón Sobre el Estado, se hace de la "concordia" aquello que convierte en certamen (benevolentium concertatio) lo que sin ella sería combate entre enemigos (lis inimicorum). Cuiden quienes hacen política competitiva merced a la Constitución pactada, que la conversión del certamen en combate, de las cañas en lanzas, no erosione la concordia que mantiene unido el cuerpo político. 